\title{
Traction-assisted colorectal endoscopic submucosal dissection using an endoloop for large semipedunculated lesions
}

Endoscopic submucosal dissection (ESD) for large semipedunculated lesions remains a challenging technique [1]. These lesions often have severe fibrosis or display muscle retracting sign during ESD. Despite the recent advantages of traction-assisted colorectal ESD [2,3], the efficacy of this technique is rarely investigated for such lesions. Here we describe a case of traction-assisted ESD using an endoloop (MAJ-254; Olympus, Tokyo, Japan) for the treatment of a large semipedunculated lesion in the right colon ( Video 1 ).

A 73-year-old man was referred to our hospital for treatment of a colonic lesion. Lower endoscopy showed a large semipedunculated lesion in the cecum, $50 \mathrm{~mm}$ in size. As technical difficulties were expected, and traction using a conventional clip was likely to tear the lesion, we attempted to obtain traction using an endoloop.

The endoloop was held alongside the scope using a grasping forceps and brought to the lesion carefully, where it was released (\$Fig. $\mathbf{1}$ ). The lesion was gently grasped with the endoloop, and then pulled toward the anal side. The traction improved visibility of the submucosal layer, facilitating the dissection procedure. The lesion was promptly resected en bloc in 35 minutes without adverse event (> Fig.2). Histological evaluation revealed Tis cancer with free margins.

As large semipedunculated lesions are heavy, traction via clip risks tearing the marginal mucosa or damaging the specimen. The endoloop maintained good traction throughout the procedure. This method is not always effective because traction cannot be applied in all directions. In addition, if colonoscope insertion is technically difficult, it could also be difficult to bring the endoloop to the lesion while grasping it. However, this method offers an alternative for technically difficult large semipedunculated lesions in colorectal ESD.

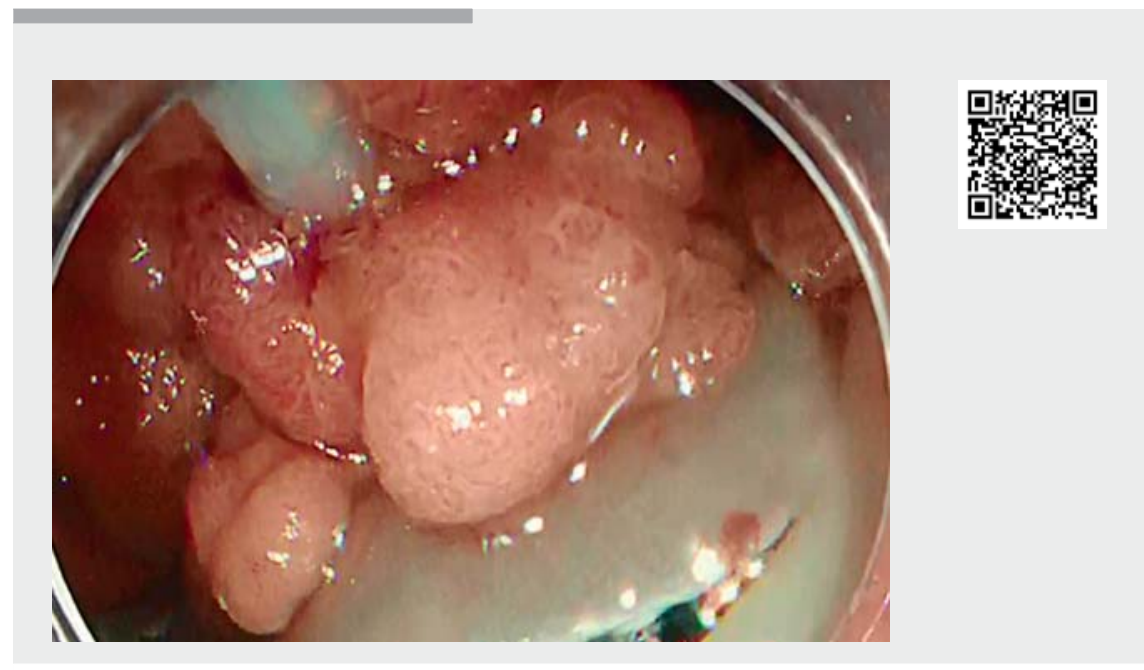

Video Traction-assisted endoscopic submucosal dissection using an endoloop facilitate the procedure for technically difficult large semipedunculated lesions.
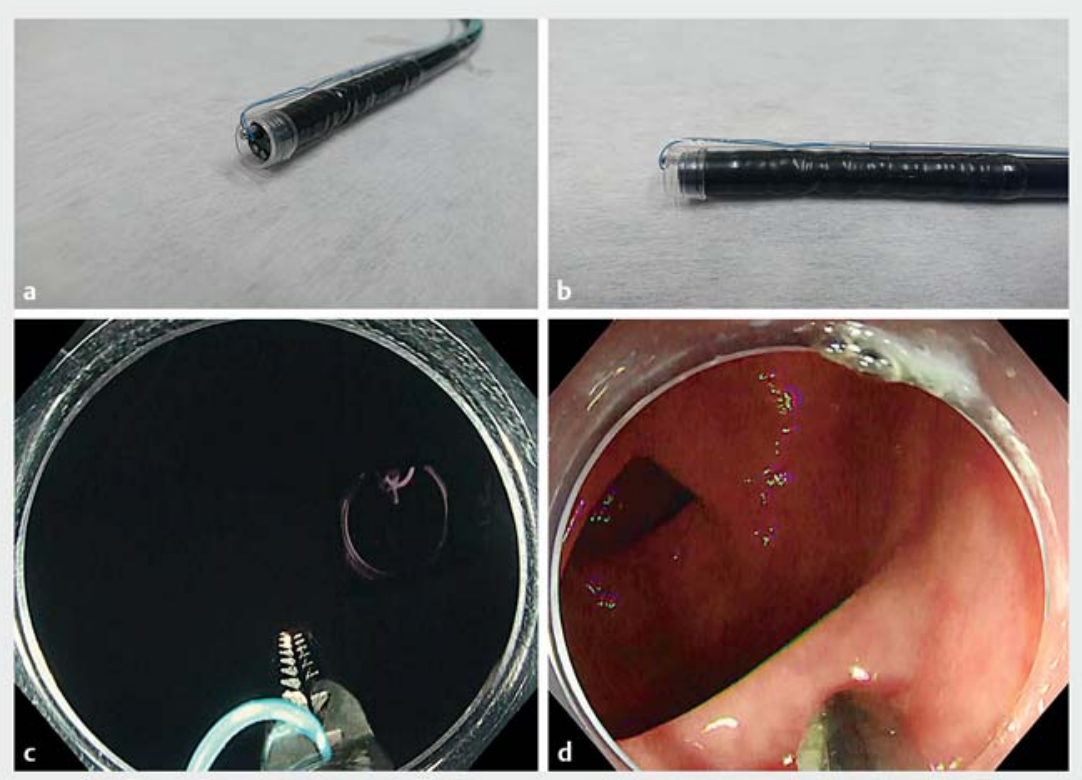

Fig. 1 Preparation for traction-assisted endoscopic submucosal dissection using an endoloop. a, b Endoloop grasped with forceps alongside the endoscope. c Grasping forceps pulled into the transparent cap. $\mathbf{d}$ Careful scope insertion close to the lesion. 

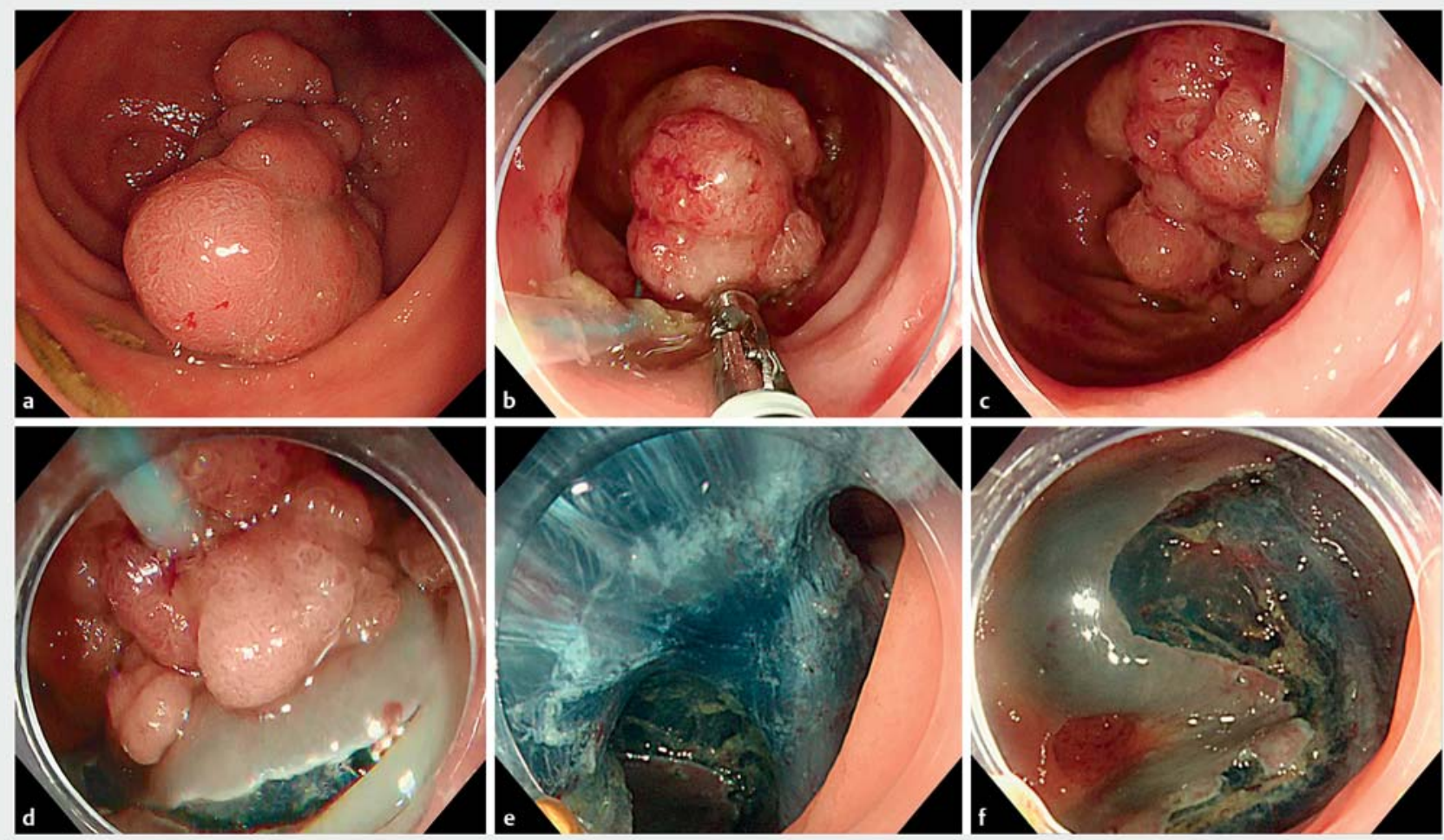

- Fig. 2 Procedure of traction-assisted endoscopic submucosal dissection (ESD) using an endoloop. a Large semipedunculated lesion located in the cecal base. $\mathbf{b}, \mathbf{c}$ Lesion gently grasped with an endoloop and pulled toward the anal side. $\mathbf{d}$, e Dissection becomes easy and safe with traction. f Mucosal defect after ESD.

Endoscopy_UCTN_Code_TTT_1AQ_2AD

\section{Competing interests}

The authors declare that they have no conflict of interest.

The authors

\section{Maiko Takita, Eiji Sakai, Takashi Muramoto,} Ken Ohata

Department of Gastrointestinal Endoscopy, NTT Medical Center Tokyo, Tokyo, Japan

\section{Corresponding author}

\section{Ken Ohata, MD, PhD}

Department of Gastrointestinal Endoscopy, NTT Medical Center Tokyo, 5-9-22 HigashiGotanda Shinagawa-ku, Tokyo 141-8625, Japan

Fax: +81-3-34486541

ken.ohata1974@gmail.com

\section{References}

[1] Choi YS, Lee JB, Lee EJ et al. Can endoscopic submucosal dissection technique be an alternative treatment option for a difficult giant $(30 \mathrm{~mm})$ pedunculated colorectal polyp? Dis Colon Rectum 2013; 56: 660-666

[2] Sakamoto N, Osada T, Shibuya T et al. The facilitation of a new traction device (S-O clip) assisting endoscopic submucosal dissection for superficial colorectal neoplasms. Endoscopy 2008; 40: E94-E95

[3] Mori H, Kobara H, Nishiyama $\mathrm{N}$ et al. Novel effective and repeatedly available ringthread counter traction for safer colorectal endoscopic submucosal dissection. Surg Endosc 2017; 31: 3040-3047

\section{Bibliography}

DOI https://doi.org/10.1055/a-1104-5082

Published online: 5.2.2020

Endoscopy 2020; 52: E279-E280

(c) Georg Thieme Verlag KG

Stuttgart · New York

ISSN 0013-726X

\section{ENDOSCOPY E-VIDEOS}

https://eref.thieme.de/e-videos

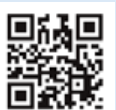

Endoscopy E-Videos is a free access online section, reporting on interesting cases and new

techniques in gastroenterological endoscopy. All papers include a high quality video and all contributions are freely accessible online.

This section has its own submission website at

https://mc.manuscriptcentral.com/e-videos 